\title{
THREE-DIMENSIONAL CFD SIMULATION OF GEYSER BOILING IN A TWO-PHASE CLOSED THERMOSYPHON
}

\author{
Hussam Jouhara ${ }^{a^{*}}$, Bandar Fadhl $^{b}$, Luiz C. Wrobel $^{b}$ \\ ${ }^{a}$ Institute of Energy Futures, RCUK Centre for Sustainable Energy Use in Food Chains (CSEF) \\ ${ }^{b}$ Institute of Materials and Manufacturing. \\ * Corresponding author. Email: hussam.jouhara@brunel.ac.uk; Tel. +44(0) 1895267805 \\ ${ }^{a, b}$ College of Engineering, Design and Physical Sciences, Brunel University London, Uxbridge, \\ Middlesex UB8 3PH, London, UK
}

Keywords: Two-phase thermosiphon; Computational fluid dynamics (CFD); Phase change material; Geyser boiling; Pool boiling; Nucleate film boiling

\section{A B S T R A C T}

This paper examines the application of CFD modelling to simulate the complex multiphase characteristics inside a wickless heat pipe (thermosyphon). Water and refrigerant R134a were selected as working fluids. A novel and comprehensive threedimensional CFD model of a wickless heat pipe was developed to simulate both the complex multiphase heat and mass transfer characteristics of boiling and condensation and the heat transfer characteristics of the cooling fluid in the condenser - heat exchanger. The CFD simulation has successfully predicted, for the first time, a boiling regime and two phase flow pattern that takes place with water at low power throughput, known as geyser boiling. The effects of the power throughput on the characteristics of the geyser boiling were investigated. The CFD simulation was also successful in modelling and visualising the multiphase flow characteristics, emphasising the difference in pool boiling behaviour between these working fluids. Temperature profiles and visual validation of the resulting 3D CDF findings were conducted using two experimental facilities. 


\section{INTRODUCTION}

Interest in the use of heat pipe technology for heat recovery and energy savings in a vast range of engineering applications has been on the rise during the recent years [1]. Heat pipes are playing a very important role in many industrial applications, especially in improving the thermal performance of heat exchangers [2] as well as an effective heat removal method in hydrogen storage systems, such as metal hydride bed [3]. Moreover, for rapid temperature management and isothermalisation, heat pipes have been further used for the thermal control of Carbon monoxide (CO) removal from a $\mathrm{CO} / \mathrm{H}_{2}$ stream [4].

Computational techniques play an important role in solving complex flow problems for a large number of engineering applications due to their universality, flexibility, accuracy and efficiency [5,6]. Wickless heat pipe systems are more desirable than conventional systems due to their passive operation, reliability, efficiency and the cost and ease of manufacturing [7]. A wickless heat pipe, also called two-phase closed thermosyphon, is a two-phase heat transfer device with a highly effective thermal conductivity, containing a small amount of working fluid that circulates in a sealed tube utilising the gravity forces to return the condensate back to the evaporator [8]. When the evaporator section is heated by an external source, the heat is transferred to the working fluid through the evaporator wall. The working fluid absorbs an amount of heat proportional to the latent heat of vaporisation, which is sufficient to change the fluid from liquid to vapour. The vapour then moves to the condenser section, where it changes phase again back to liquid, along the condenser's wall, giving up its latent heat absorbed in the evaporator section. The condensed liquid is then returned to the evaporator due to gravitational or capillary forces, according to the type of heat pipe $[8,9]$. Two-phase closed thermosyphons have been extensively used in many applications [10]; however, up to now, computational numerical studies on heat pipes, displaying the complex two-phase flow inside the heat pipe, are at an early stage.

Kafeel and Turan [11] studied the effect of different pulsed increases of the heat input at the evaporator zone on the behaviour of the thermosyphon. They used similar thermosyphon configurations to that of Amatachaya et al. [12] to validate their 
simulation model, and an Eulerian model to simulate the film condensation at the condenser zone, with a filling ratio of $30 \%$ of the evaporator zone. Alizadehdakhel et al. [13] focused on a two-dimensional model simulation and experimental studies, in which they investigated the effect of the input heat flow and the filling ratio of the working fluid on the performance of a two-phase closed thermosyphon, using water as a working fluid. Zhang et al. [14] developed a two-dimensional model of a diskshaped flat two-phase thermosyphon used for electronics cooling. The authors simulated the flow inside the disk flat two-phase thermosyphon as a single-phase flow with water as the working fluid. They compared the distribution of the vapour velocity and temperature with the experimental results, in order to determine the factors affecting the axial thermal resistance of flat thermosyphons. Annamalai and Ramalingam [15] carried out an experimental investigation and CFD analysis of a wicked heat pipe using ANSYS CFX. The authors considered the region inside the heat pipe as a single phase of vapour and the wick region as the liquid phase, and used distilled water as the working fluid. They compared the predicted surface temperature along the evaporator and condenser walls and the vapour temperature inside the heat pipe with their experimental data. Lin et al. [16] built a CFD model to predict the heat transfer capability of miniature oscillating heat pipes (MOHPs) using VOF and Mixture models, and water as the working fluid. The effects of different heat transfer lengths and inner diameters at different heat inputs were used to analyse the heat transfer capability of MOHPs.

Khazaee et al. [17] experimentally investigated the geyser boiling phenomenon in a two-phase closed thermosyphon for water as a working fluid. They investigated the effects of filling ratio, aspect ratio, heat input and coolant mass flow rate on geyser boiling by testing the period of the geyser boiling. They found that, by increasing the heat throughput to the evaporator section, the period of the geyser boiling decreased and eventually disappeared with further increase in the heat throughput. They also observed that the period of geyser boiling increased when the filling ration increased from $35 \%$ to $60 \%$. Lin et al. [18] also carried out an experimental investigation of the geyser boiling in a two-phase closed thermosyphon. They investigated the influence of different parameters on the characteristics of the geyser boiling for water and ethanol as working fluids. Among the investigated parameters was the heat load, and 
they found that the period of the geyser boiling was shorter for a higher heat throughput and the temperature oscillation showed a little irregularity. They concluded that the period of the geyser boiling decreased linearly with the heat throughput. The effects of the fill ratio of the working fluid and the inclination angle of a two-phase closed thermosyphon were experimentally investigated by Negishi and Sswada [19]. They reported that for fill ratios higher than $70 \%$,a strange sound was heard, caused by a large mass of the working fluid being pushed up to the end of the condenser section by the sudden expansion of a boiling bubble. They called this phenomenon water hammer, and stated that it could cause damage to the contained wall if it continues for a long time.

There is an obvious gap in the published literature on CFD simulations of two-phase heat transfer/flow within a wickless heat pipe. Fadhl et al. [8] considered the phase change material by implementing the appropriate source terms in the flow governing equations, using User Defined Functions (UDFs). These source terms, determining the mass and heat transfer between the liquid and vapour phases, have been linked to the main hydrodynamic equations of FLUENT. The two-dimensional CFD results of Fadhl et al. $[8,20]$ show that FLUENT with the VOF and UDFs can successfully model the complex two-phase flow phenomena inside the thermosyphon.

The purpose of this paper is to extend the work of Fadhl et al. $[8,20]$ by building a three-dimensional CFD model to simulate the two-phase flow and mass/heat transfer phenomena of boiling and condensation, including the simulation of the condenser water jacket. The CFD model has successfully predicted and visualised the geyser boiling phenomenon, which has not been reported before in previous studies. The pool boiling behaviour has been investigated for different working fluids, namely water and R134a. The effects of high and low power throughput on the characteristics of the geyser boiling have been investigated. The reported work focuses on the flow visualisation of the two-phase flow during the operation of a wickless heat pipe. A transparent glass wickless heat pipe charged with water was used to observe and visualise the geyser boiling process mathematical model. 


\section{MATHEMATICAL MODEL}

The governing equations of mass continuity, momentum and energy are used to describe the motion of the working fluid in a thermosyphon. This will be explained in the next section.

\subsection{CONTINUITY EQUATION FOR VOF MODEL (VOLUME FRACTION EQUATION)}

By applying the physical principle of conservation of mass to the fluid, the continuity equation has the following form [20]:

$$
\nabla \cdot(\rho \mathbf{V})=-\frac{\partial \rho}{\partial t}
$$

where $\rho$ is the density, $\mathbf{V}$ is the velocity vector and $t$ is the time.

Solution of the above equation for the volume fraction of one of the phases is used to track the interface between the phases. Thus, the continuity equation of the VOF model for the secondary phase $(l)$ can be expressed as [21]:

$$
\nabla \cdot\left(\alpha_{l} \rho_{l} \mathbf{V}\right)=-\frac{\partial}{\partial t}\left(\alpha_{l} \rho_{l}\right)+S_{m}
$$

where $S_{m}$ is the mass source term used to calculate the mass transfer during evaporation and condensation.

The continuity equation shown above can be called the volume fraction equation and this relation will not be solved for the primary phase as the volume fraction of the primary-phase is determined based on the following constraint [21]:

$$
\sum_{l=1}^{n} \alpha_{l}=1
$$

When the cell is not fully occupied by the primary phase $(v)$ or the secondary phase $(l)$, a mixture of the phases $l$ and $v$ exists. Thus, the density of the mixture is given as the volume-fraction-averaged density and takes the following form [21]:

$$
\rho=\alpha_{l} \rho_{l}+\left(1-\alpha_{l}\right) \rho_{v}
$$




\subsection{MOMENTUM EQUATION FOR VOF MODEL}

The forces acting in the fluid were considered to be gravitational, pressure, friction and surface tension. In order to consider the effect of surface tension along the interface between the two phases, the continuum surface force $(C S F)$ model proposed by Brackbill et al. [22] has been added to the momentum equation

$$
\mathbf{F}_{C S F}=2 \sigma \frac{\alpha_{l} \rho_{l} C_{v} \nabla \alpha_{v}+\alpha_{v} \rho_{v} C_{l} \nabla \alpha_{l}}{\rho_{l}+\rho_{v}}
$$

where $\sigma$ is the surface tension coefficient and $C$ is the surface curvature.

By taking into account the above forces, the momentum equation for the VOF model takes the following form [20]:

$$
\begin{aligned}
\frac{\partial}{\partial t}(\rho \mathbf{V})+\nabla \cdot & \left(\rho \mathbf{V} \mathbf{V}^{T}\right) \\
& =\rho \mathbf{g}-\nabla p+\nabla \cdot\left[\mu\left(\nabla \mathbf{V}+(\nabla \mathbf{V})^{\boldsymbol{T}}\right)-\frac{2}{3} \mu(\nabla \cdot \mathbf{V}) \mathbf{I}\right]+\mathbf{F}_{C S F}
\end{aligned}
$$

where $\mathrm{g}$ is the acceleration of gravity, $p$ is the pressure and $\boldsymbol{I}$ is the unit tensor.

The momentum equation depends on the volume fraction of all phases through the physical properties of density and viscosity [21]. Thus, the dynamic viscosity $\mu$ is given by

$$
\mu=\alpha_{l} \mu_{l}+\left(1-\alpha_{l}\right) \mu_{v}
$$

A single momentum equation is solved through the computational domain, and the calculated velocity is shared among the phases.

\subsection{ENERGY EQUATION FOR VOF MODEL}

The energy equation for the VOF model has the following form [20]:

$$
\frac{\partial}{\partial t}(\rho E)+\nabla \cdot(\rho E \mathbf{V})=\nabla \cdot(k \nabla T)+\nabla \cdot(p \mathbf{V})+S_{E}
$$


where $S_{E}$ is the energy source term used to calculate the heat transfer during evaporation and condensation.

The VOF model treats the temperature $T$ as a mass-averaged variable and the thermal conductivity $k$ is calculated as [21]:

$$
k=\alpha_{l} k_{l}+\left(1-\alpha_{l}\right) k_{v}
$$

The VOF model also treats the energy $E$ as a mass-averaged variable in the following form [21]:

$$
E=\frac{\alpha_{l} \rho_{l} E_{l}+\alpha_{v} \rho_{v} E_{v}}{\alpha_{l} \rho_{l}+\alpha_{v} \rho_{v}}
$$

where $E_{l}$ and $E_{v}$ are based on the specific heat $C_{v}$ of the phase and the shared temperature, given by the caloric equation of state [20]:

$$
\begin{aligned}
& E_{l}=c_{v, l}\left(T-T_{s a t}\right) \\
& E_{v}=c_{v, v}\left(T-T_{s a t}\right)
\end{aligned}
$$

A single energy equation is also solved throughout the domain for both phases, and the calculated temperature is shared among the phases.

\section{MODEL GEOMETRY AND COMPUTATIONAL MESH}

A three-dimensional model was developed to simulate the two-phase flow in a wickless heat pipe. According to the experimental configuration described in [23], the specifications of a small two-phase closed thermosyphon for this model are as follow:

Material: copper

Working fluid: water

Evaporator section length: $\mathbf{4 0 m m}$

Adiabatic section length: 100mm

Condenser section length: $\mathbf{6 0 m m}$

Inner diameter: $\mathbf{6 m m}$

Outer diameter: 12mm 
Wall thickness: 3mm

Figure 1 shows the three-dimensional model geometry and dimensions.

The computational mesh used in the simulation of the two-phase closed thermosyphon with water jacket is illustrated in Figure 2. At the near inner wall of the thermosyphon, ten layers of cells are used in order to capture the thin liquid film that develops in that region. Another ten layers of cells are used near the outer wall of the condenser section, in order to capture the forced convection heat transfer between the condenser section and the cooling water, as shown in Figure 2. As a result, 370,702 cells are used for the simulations. The above number of cells was limited by the computing resources available for the present work, which precluded a more detailed convergence analysis.

\section{BOUNDARY CONDITIONS AND CFD SOLUTION PROCEDURE}

A transient simulation was carried out to model the dynamic behaviour of the twophase flow. A variable time stepping technique has been used in order to automatically change the time-step based on the maximum Courant number near the interface. A combination of the SIMPLE algorithm for pressure-velocity coupling and a first-order upwind scheme for the determination of momentum and energy is selected in the model. PRESTO and Geo-Reconstruct discretization for the pressure and volume fraction interpolation scheme, respectively, are also performed in the model.

The vapour phase of the working fluid was defined as the primary phase and the liquid phase was defined as the secondary phase. The VOF method and UDFs have been employed in the model, by implementing the appropriate source terms in the flow governing equations. These source terms, determining the mass and heat transfer between the liquid and vapour phases, have been linked to the main hydrodynamics equations of FLUENT. The details of the UDFs, relevant to this study, have been discussed by Fadhl et al. [8,20]. 
A non-slip boundary condition was imposed at the inner walls of the thermosyphon. Heat was applied to the thermosyphon by defining a constant heat flux at the wall of the evaporating section. A zero heat flux was defined as boundary condition on the adiabatic section. The upper and lower caps of the thermosyphon were also defined as adiabatic. The interfaces (i.e. inner walls) between the solid and fluid regions of the water jacket and heat pipe, as shown in Figure 2, were defined as coupled wall boundary condition, so as to allow heat to transfer between the solid and fluid zones.

The condenser section was a double pipe heat exchanger, cooled by a flow of water, as can be seen in Figure 1. The heat exchanger consisted of two concentric pipes, where the saturated vapour flows through the condenser pipe and the cooling fluid flows through the annular space between the two pipes. The outer wall of the water jacket was considered as adiabatic. The cooling water inlet was defined as a mass flow inlet with a constant flow rate of $0.001329 \mathrm{~kg} / \mathrm{s}$ [24], while the cooling water outlet was defined as a pressure outlet. Water and refrigerant R134a have been used as the working fluids and filled the total volume of the evaporator section (i.e. $\mathrm{FR}=1.0$ ). The mesh adaption facility in FLUENT was used to define the fill ratio of the working fluid in the fluid region. The thermophysical properties of the working fluid were assumed to be constant to limit the calculation time. 


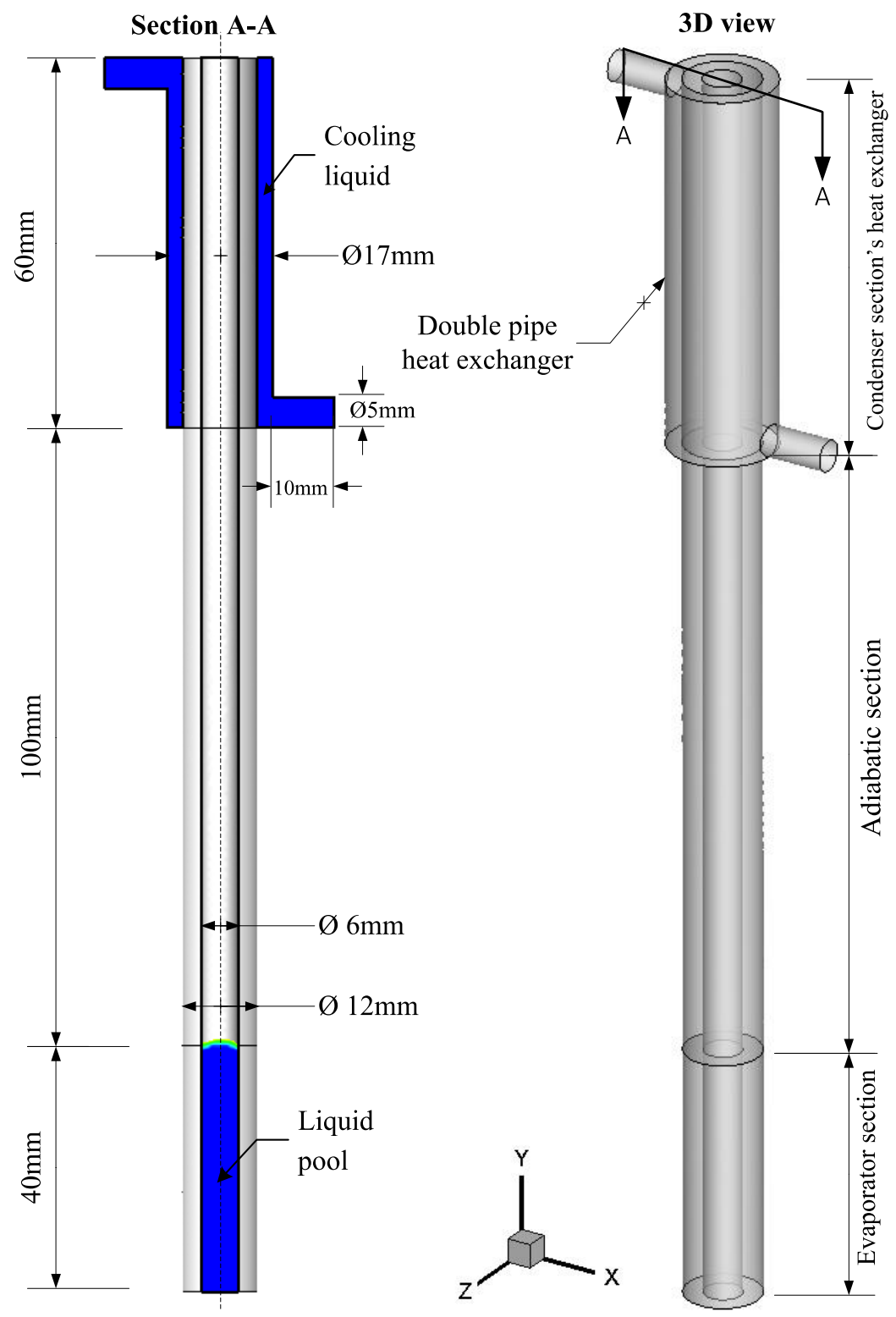

Figure 1: 3D model geometry and dimensions of two-phase closed thermosyphon with water jacket 


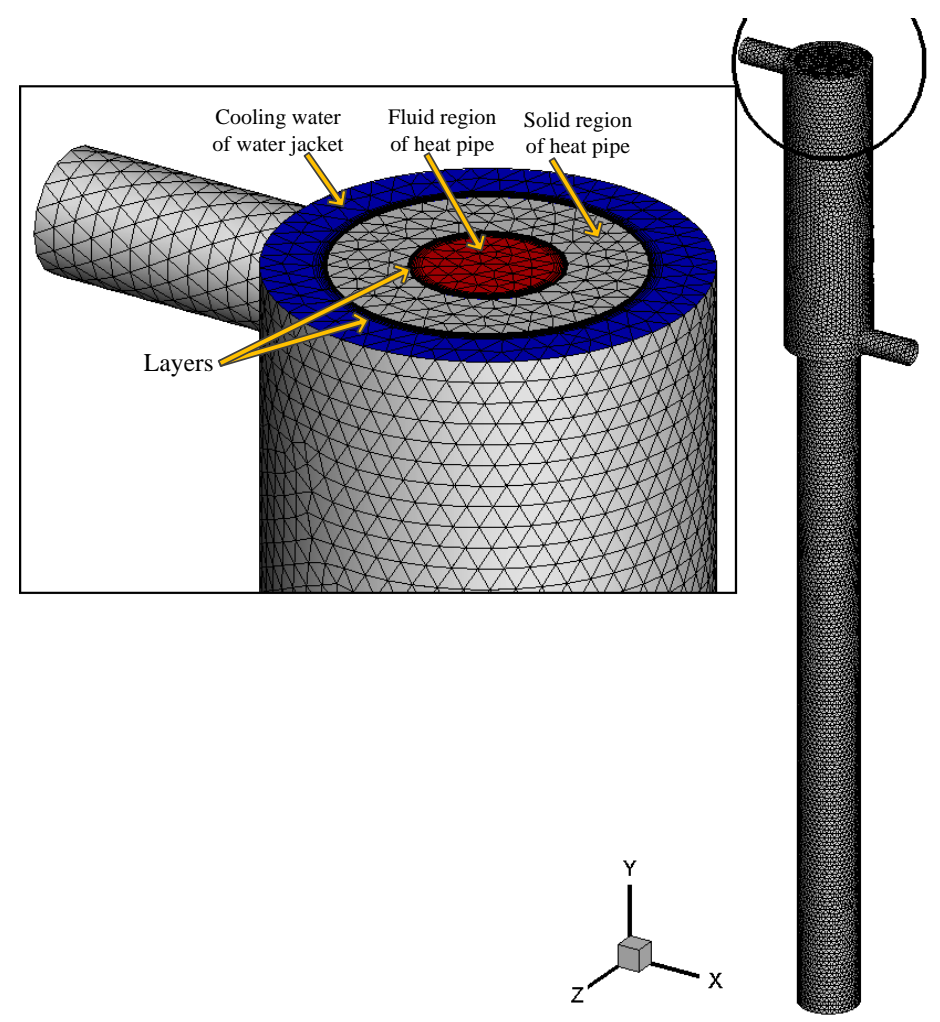

Figure 2: The computational mesh used in the simulation of a two-phase closed thermosyphon with water jacket

\section{FLOW VISUALISATION OF CFD SIMULATION RESULTS}

In the following sub-section, the CFD simulation findings will be visualised and the pool boiling process within the water-filled thermosyphon will be discussed. Furthermore, during the flow visualisation of the boiling process, a flow pattern has been noticed at low power throughput.

To investigate further this observation, an experimental apparatus to validate the CFD outputs was set up to allow variable power throughputs through a thermosyphon under steady state conditions. The used experimental facility is shown in Figure 3.

The thermosiphon was charged with water as a working fluid at a 50\% filling ratio. The data from the two thermocouples that measure the wall temperatures $T_{e 1}$ and $T_{e 2}$ were used to collect the wall temperature in the pool boiling and nucleate film boiling 
regions. Details of the operational procedures, data reduction and analysis are reported by Jouhara and Robinson [23].

The boiling pattern that is noticed at low power throughput into the thermosiphon is known as geyser boiling. This boiling mode, which will be discussed in a later section, is observed when boiling water at low heat fluxes and relatively smooth surfaces where the number of active nucleation sites is limited. The locations of the thermocouple measuring $T_{e 1}$ and $T_{e 2}$ are further illustrated in Figure 4.

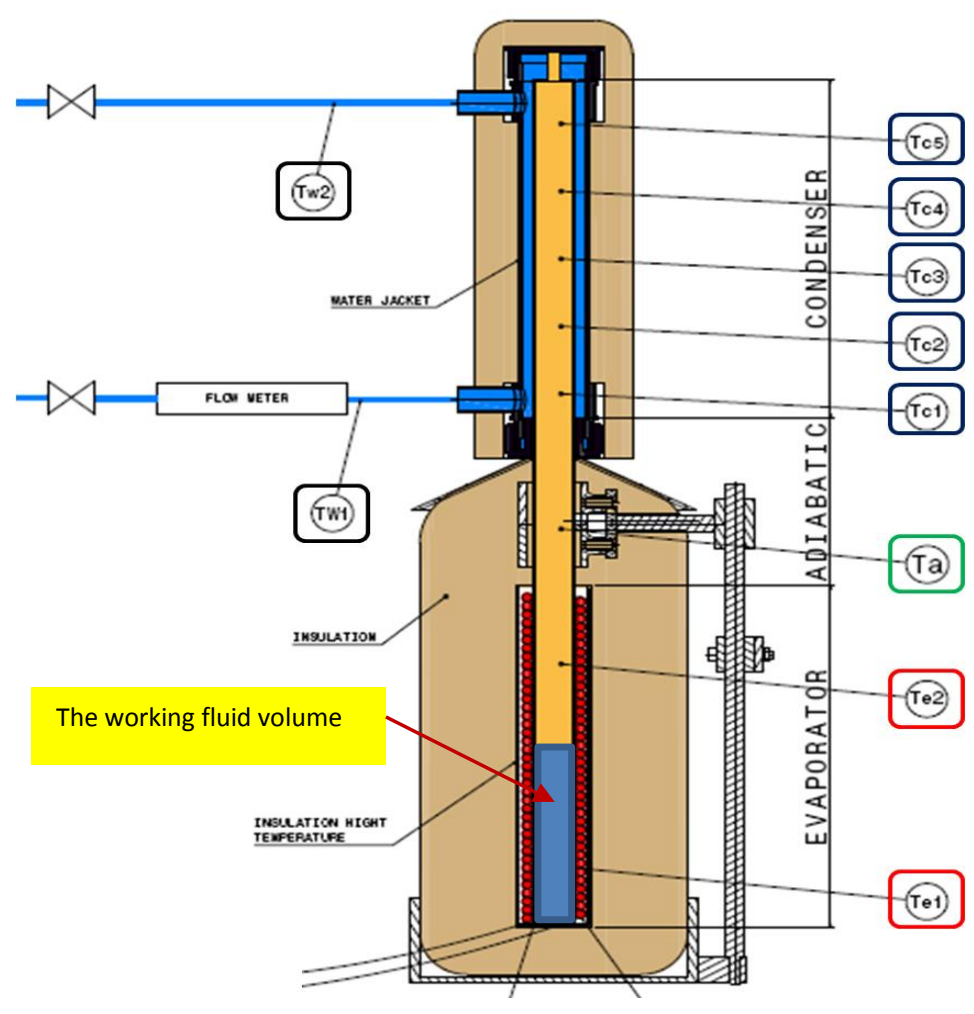

Figure 3. The experimental apparatus

As it can be seen in Figure 4, $T_{e 1}$ is the temperature of the wall that encloses the bulk of the working fluid in the thermosiphon that undergoes pool boiling during steady state conditions. $T_{e 2}$ is the wall temperature that has nucleate film boiling of the working fluid condensate that flows back from the condenser. 


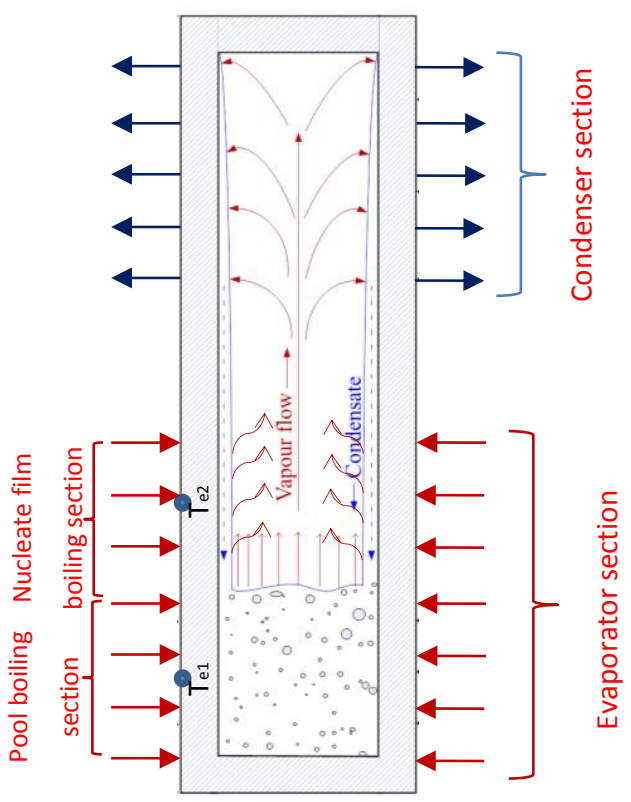

Figure 4. Thermocouple locations for the measurements of $T_{e 1} \& T_{e 2}$

Steady state heat transfer conditions through the thermosyphon were achieved for heat evaporator heat fluxes of between $14 \mathrm{~kW} / \mathrm{m}^{2}$ and $36 \mathrm{~kW} / \mathrm{m}^{2}$, corresponding to 100 $\mathrm{W}$ to $250 \mathrm{~W}$, respectively. As it can be seen in Figure 5, typical geyser boiling regime is evident at low heat fluxes where the wall that surrounds the pool boiling regime experienced superheating until the nucleation site was activated. This effect on the wall that surrounds the nucleate film boiling region is also clear especially when the bubble departs the pool boiling area. 


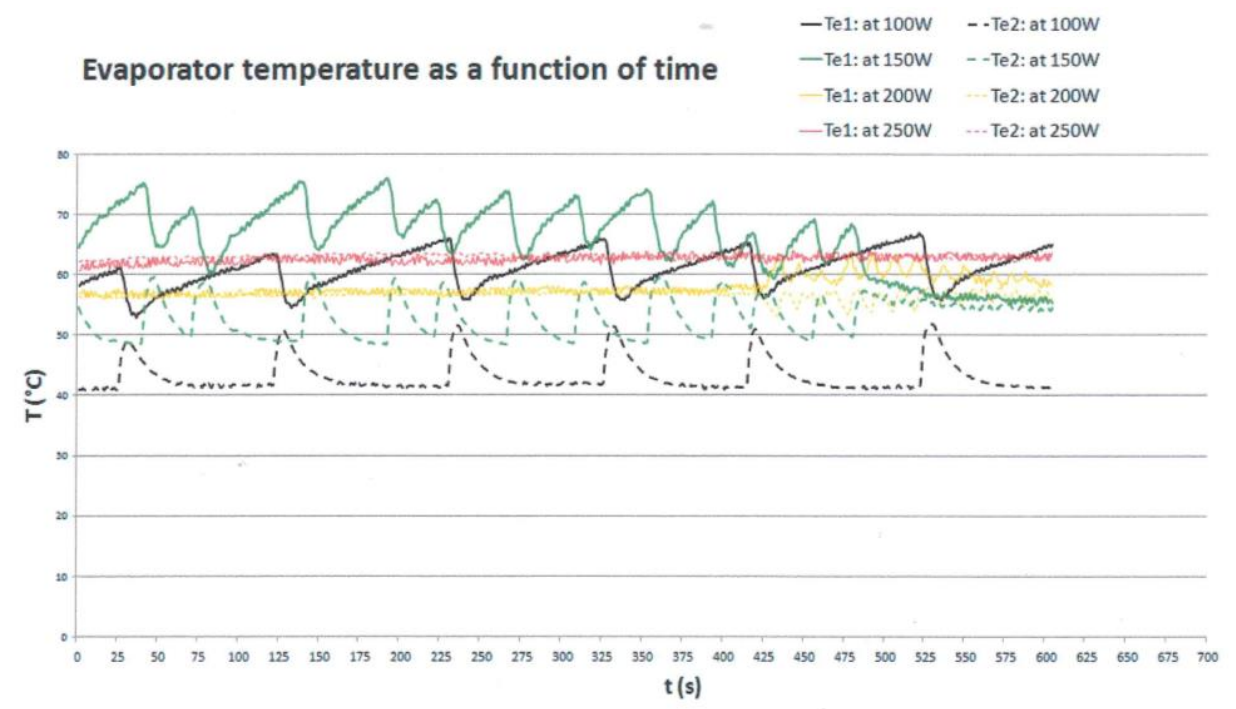

Figure 5. Evaporator temperatures for water-filled thermosyphon at different power throughputs

Comparing the characteristics of the geyser boiling with the flow visualisation of the CFD modelling, as will be discussed in later sections, it can be noticed that the threedimensional CFD simulation is successfully modelling geyser boiling in a thermosyphon at low power throughput.

Consequently, in the following sub-sections, the geyser boiling phenomenon will be briefly described, the CFD simulation findings will be visualised and the geyser boiling process within the water-filled thermosyphon, for a high and low power throughput will be discussed.

\subsection{GEYSER BOILING}

Geyser boiling is a phenomenon affected by many factors, such as heat load and filling ratio, and occurs in two-phase thermosyphons when the liquid fill ratio in the evaporator section is large and heat input is insufficient. Figure 6 presents a schematic of the geyser boiling phenomenon [17]. When the liquid pool in the evaporator section is gradually heated until it becomes superheated, a vapour bubble grows and expands to the size of the inner diameter of the thermosyphon. This bubble then blow-up suddenly, pushing all the liquid above it, causing the evaporator wall temperature to suddenly drop in the pool boiling section while that in the nucleate 
film boiling and the condenser is suddenly raised due to the pushed hot liquid coming from the lower half of the evaporator. This hot liquid then starts to fall back to the evaporator, causing the condenser wall temperature to drop. The geyser boiling phenomenon can be recognised by a special sound. The falling liquid from the condenser then reaches the evaporator and gradually heats up again and starts another cycle of geyser boiling. Thus, a zigzag temperature variation in the evaporator wall has been observed, as clearly seen in Figure 5.

While the above behaviour can be interpreted using eth thermocouples measurements, a visual validation is required to validate the CFD findings. To facilitate the visual validations, a transparent glass thermosyphon filled with water has been used to visualise the phenomena of geyser boiling and compare $i$ with the flow visualisation findings of the three-dimensional CFD simulation.

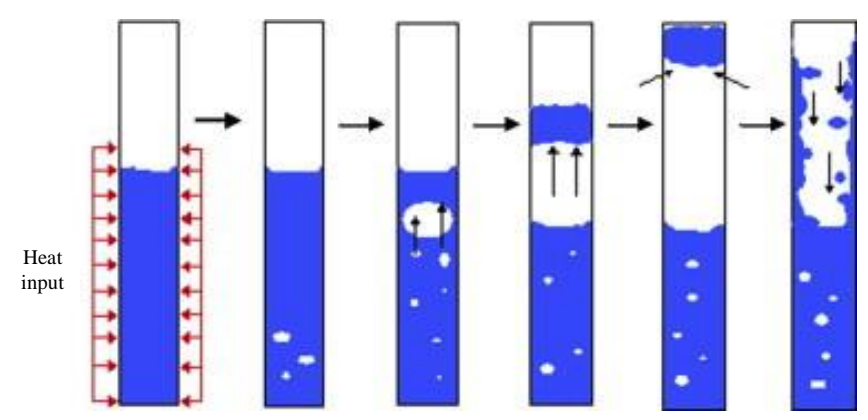

Figure 6: Schematic of geyser boiling process in a thermosyphon [18]

\subsection{THREE-DIMENSIONAL CFD SIMULATION OF A WATER-FILLED THERMOSYPHON FOR A POWER THROUGHPUT OF 30W}

The geyser boiling phenomenon generated inside the thermosyphon occurs when the water is superheated near the bottom of the evaporator, creating a nucleation site and leading to a large vapour bubble which expands to the size of the inner diameter of the thermosyphon. When the buoyancy of that bubble becomes higher than the weight of the water column above the bubble, the bubble quickly pushes the entire water column above it and produces a strange sound in the thermosyphon [18]. 
The process of geyser boiling described above is observed in the CFD flow visualisation shown in Figure 7. In this visual observation, the volume fraction contours of the fluid region in the thermosyphon for a power throughput of $30 \mathrm{~W}$ has been monitored for different times. Vapour bubbles that appear in the evaporator section during the geyser boiling process and take the size of the inner diameter of the evaporator are shown in Figure 8.

The water pool is represented by the blue colour and the vapour is represented by the red colour, as can be seen in Figure 7 and Figure 8. The water has initially filled the total volume of the evaporator section, as shown in Figure 7 at $t=0.0 \mathrm{~s}$. The water is heated and at a certain time, vapour bubbles start to form in the evaporator, as shown in Figure 7 at $\mathrm{t}=0.12 \mathrm{~s}$. Vapour bubbles then grow and expand almost to the size of the inner diameter of the thermosyphon, specially at the top region of the evaporator section, which is clearly shown in Figure 8. As a result, the geyser boiling regime starts and the bubble quickly expels the water above it, as shown in Figure 7 at $t=3.0$ s. The water expelled by the bubble then starts to fall back and the geyser boiling cycle is completed, as shown in Figure 7 at $t=3.1 \mathrm{~s}$. Later, another cycle of geyser boiling starts as the next bubble appears and grows, as seen in Figure 7 at $\mathrm{t}=4.0 \mathrm{~s}$ and $5.0 \mathrm{~s}$. Furthermore, it is observed from the figure that the surface of the water pool has been raised due to the bubbles forming at a large number of nucleation sites, which form continuous columns of vapour bubbles in the liquid pool. 


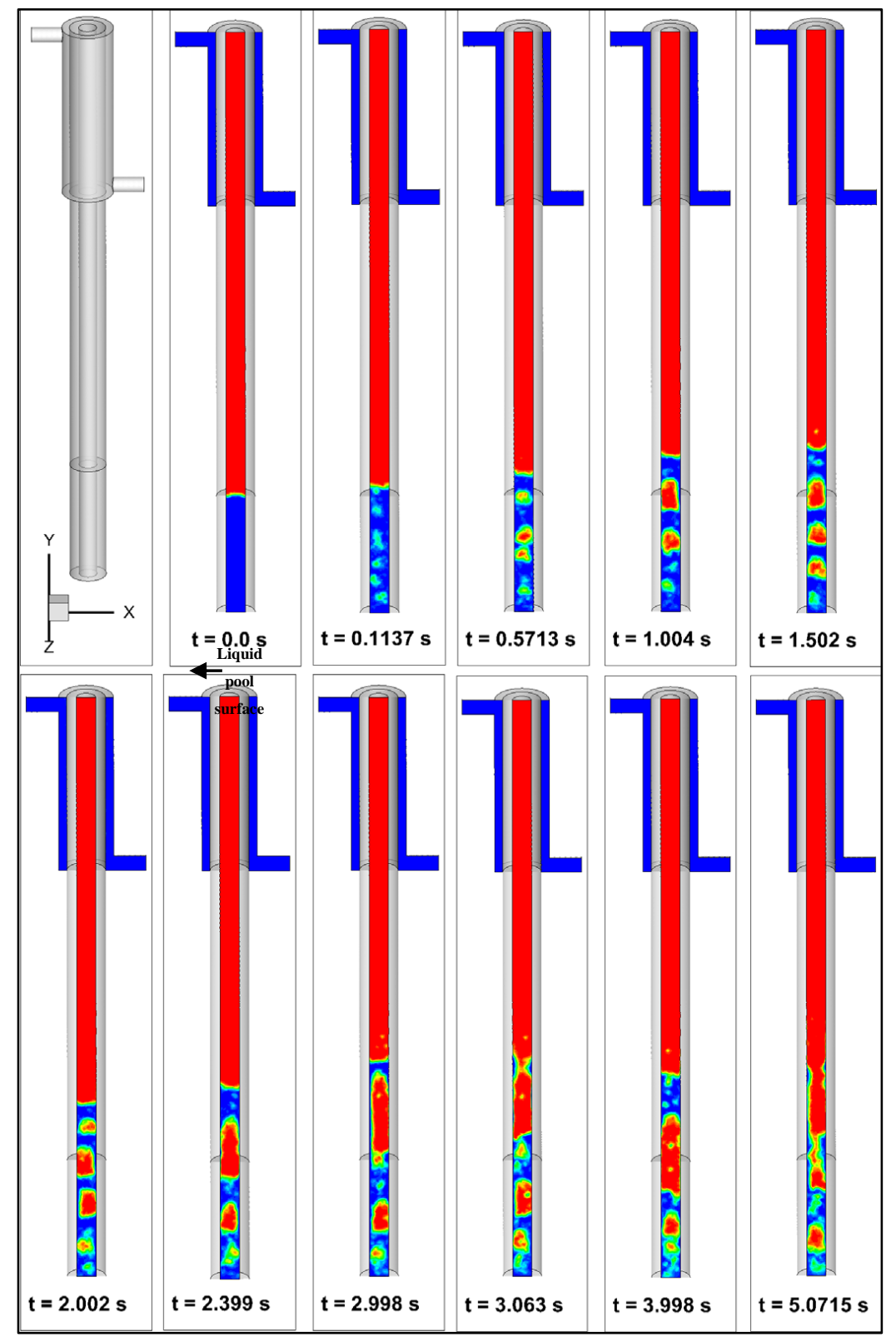

Figure 7: Geyser boiling process in a thermosyphon for a power throughput of $30 \mathrm{~W}$ 


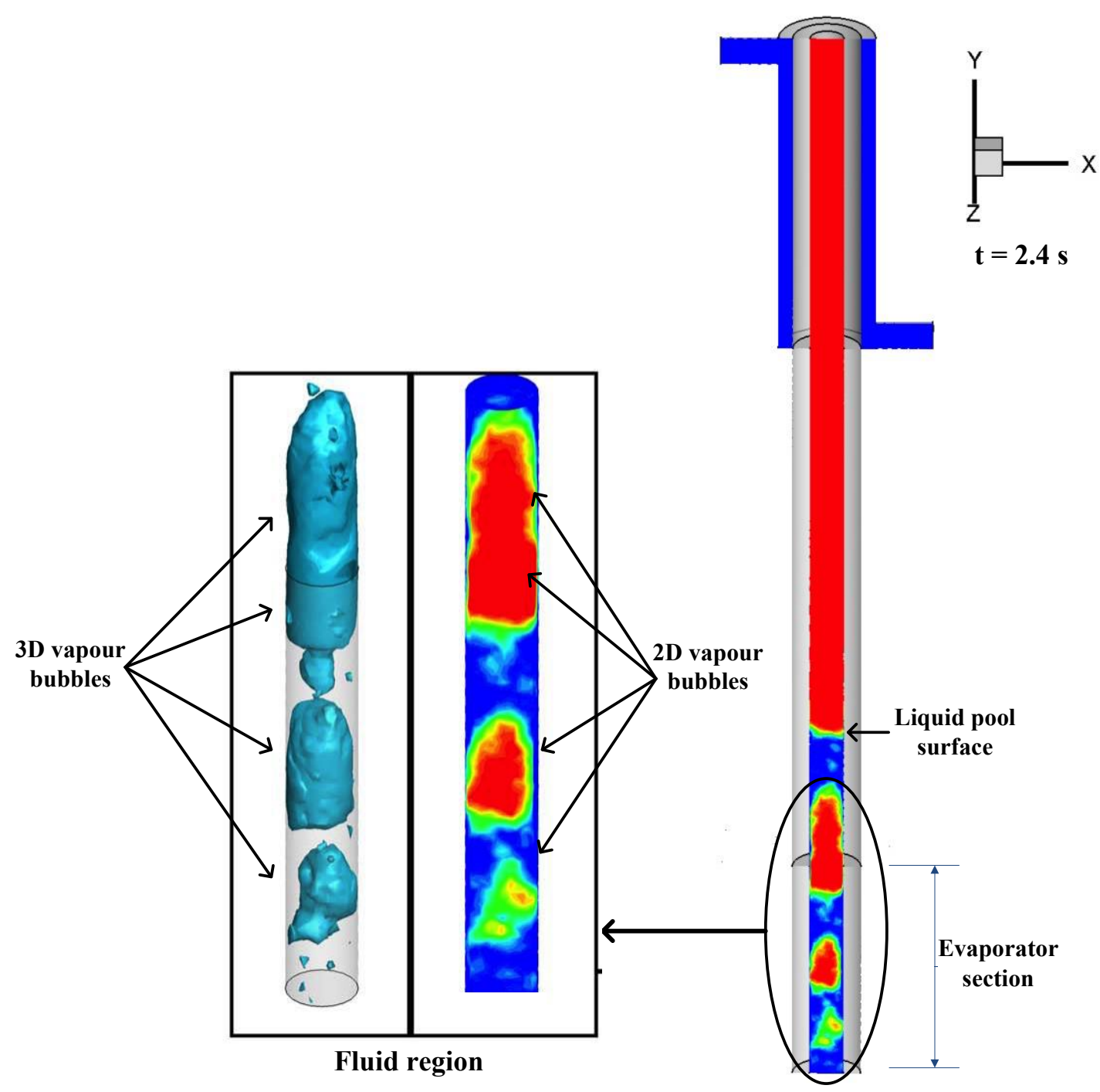

Figure 8: Size of the vapour bubbles in the evaporator section for a power throughput of $30 \mathrm{~W}$

\subsection{THREE-DIMENSIONAL CFD SIMULATION OF A WATER-FILLED THERMOSYPHON FOR A POWER THROUGHPUT OF 220W}

In order to understand the effects of the power throughput on the boiling characteristics, flow visualisation of the pool boiling at a high power throughput is also conducted for the water-filled thermosyphon. Figure 9 shows the volume fraction contours of the fluid region in the evaporator and in the lower adiabatic region for a power throughput of $220 \mathrm{~W}$. The figure includes both the three-dimensional vapour 
bubbles in the liquid pool and a cross-section of the evaporator and the lower adiabatic region for different simulation times.

The water is heated and at a certain time, vapour bubbles start to form in the evaporator, as shown at $0.02 \mathrm{~s}$. It can also be noted from the figure that a high number of small bubbles nucleation sites is observed on the evaporator inner wall, as can be seen between $0.02 \mathrm{~s}$ and $0.05 \mathrm{~s}$. This can be explained by the fact that the evaporator wall at high power throughput is superheated well above the temperature required for the onset of nucleation boiling. As a result of this, the water pool is unstable and in vigorous irregular motion, which is clearly shown in the figure between $0.02 \mathrm{~s}$ and $0.05 \mathrm{~s}$ at the upper region of the evaporator. In contrast, for the low power throughput, the water pool is stable and been in quiescent condition, as shown in Figure 7 at $0.1 \mathrm{~s}$. By continuous nucleation, a large number of isolated vapour bubbles form and rise all the way up to the top region of the liquid pool before breaking up and releasing their vapour content. This is illustrated between $0.07 \mathrm{~s}$ and $0.15 \mathrm{~s}$. Furthermore, it is observed from the figure that some large vapour bubbles are formed later in the liquid pool and, as a result, the water pool surfaces rises upward, as shown in the figure between $0.16 \mathrm{~s}$ and $0.2 \mathrm{~s}$.

The above discussion refers to the short period of time between $0.0 \mathrm{~s}$ and $0.2 \mathrm{~s}$, and that is explained by the high frequency of the evaporator wall temperature profiles given in Figure 5 for high power throughputs of $200 \mathrm{~W}$ and $250 \mathrm{~W}$, while the temperature profile for low power throughput has low frequency of bubble formation, as shown in Figure 5 for $100 \mathrm{~W}$ and 150W.

It should be noted that the geyser boiling phenomenon disappears with the high power throughput and this is due to the presence of a large number of vapour bubbles in the liquid pool, which move upward fast; hence, a very large size vapour bubble, as shown in Figure 8, has not been observed. 


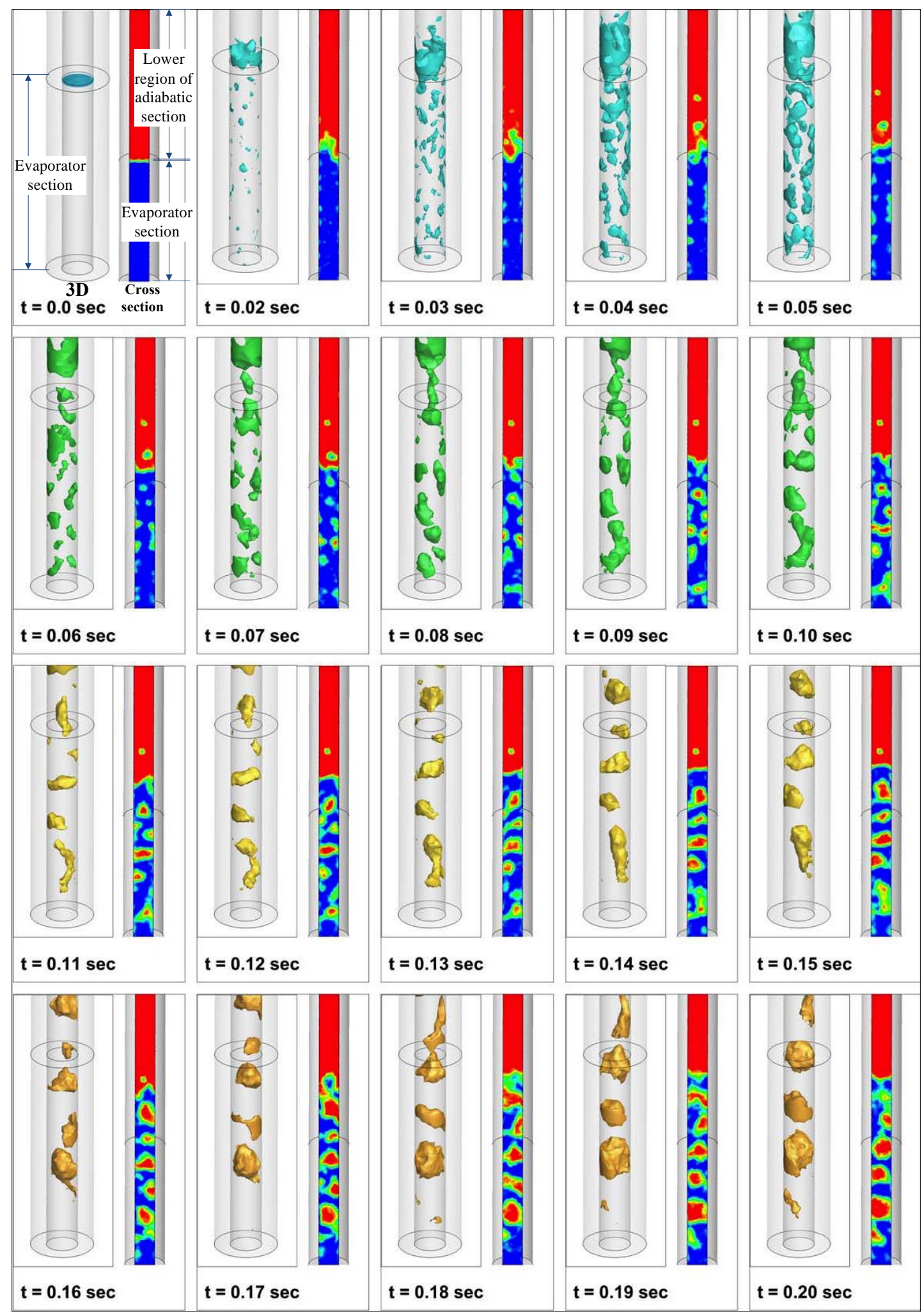

Figure 9: Pool boiling process in a thermosyphon for a power throughput of $220 \mathrm{~W}$ 


\section{A TRANSPARENT GLASS THERMOSYPHON EXPERIMENTAL APPARATUS AND PROCEDURE}

In order to show that the three-dimensional CFD simulation has successfully modelled the geyser boiling phenomenon in a thermosyphon at low power throughput, a transparent glass thermosyphon charged with water has been used to observe and visualise the process.

\subsection{EXPERIMENTAL STRUCTURE}

The glass thermosyphon contains a glass water jacket embedded on the pipe to ensure no leaks appear when cooling fluid flows through the jacket. The cooling fluid flowing through the jacket will remove the heat rejected from the condenser section.

Figure 10 shows a schematic diagram of the experimental apparatus used in this study. The apparatus consists of the glass thermosyphon, framework, cooling water flow circuit and instrumentation.

As can been seen in Figure11, the glass thermosyphon is manufactured with a $17.5 \mathrm{~mm}$ outer diameter, $440 \mathrm{~mm}$-long smooth glass tube with a wall thickness of $1 \mathrm{~mm}$. It contains a $113 \mathrm{~mm}$-long evaporator section, a $167 \mathrm{~mm}$-long adiabatic section and a 160mm-long condenser section.

\subsection{EXPERIMENTAL PROCEDURE}

At the start of the experiment, the water flow meter is turned on to allow cooling water to flow through the water jacket. A cooling water mass flow rate of $550 \mathrm{ccm}$ (i.e. $0.008317 \mathrm{~kg} / \mathrm{s}$ ) is set on the hydronic side of the equipment for the test. The visualisation of the geyser boiling is carried out by immersing the glass thermosyphon into a flask containing boiling water to supply heat to the evaporator section. The glass thermosyphon is then kept immersed in the flask until the geyser boiling phenomenon takes place, which is monitored using a digital camera recorder. Geyser boiling continues to occur until all the energy of the boiling water in the flask is dissipated. Figure 12 demonstrates the framework of the glass thermosyphon experimental apparatus. 


\subsection{EXPERIMENTAL DISCUSSION}

The footage frames recorded during the geyser boiling process in the evaporator section of the glass thermosyphon are shown in Figure 13. The initial stage of the geyser boiling process is known as the quiescent period, where the temperature of the water pool in the evaporator section gradually increases as it absorbs heat, as shown in Figure 13 (a). The water then becomes superheated and a nucleation site is created; as a result, a single vapour bubble appears at the bottom of the evaporator section, as shown in Figure 13 (b). This bubble then grows quickly to a large size, equal to the inner diameter of the evaporator section, and suddenly the growing bubble pushes up the water above it from the evaporator to the condenser producing a special sound, as shown in Figure 13 (c). Consequently, a very small volume of the water pool remains in the evaporator section, as shown in Figure 13 (d). The pushed water then falls down from the condenser and a liquid film can be seen on the inner wall, as shown in Figure 13 (e). The above described process then repeats again once the returned water is heated for another cycle, as shown in Figure 13 (f). It should be noted that due to the limitation of the resolution of the digital camera, the figure (c) is not clearly visualised the very small period of time of the pushed water in the evaporator section.

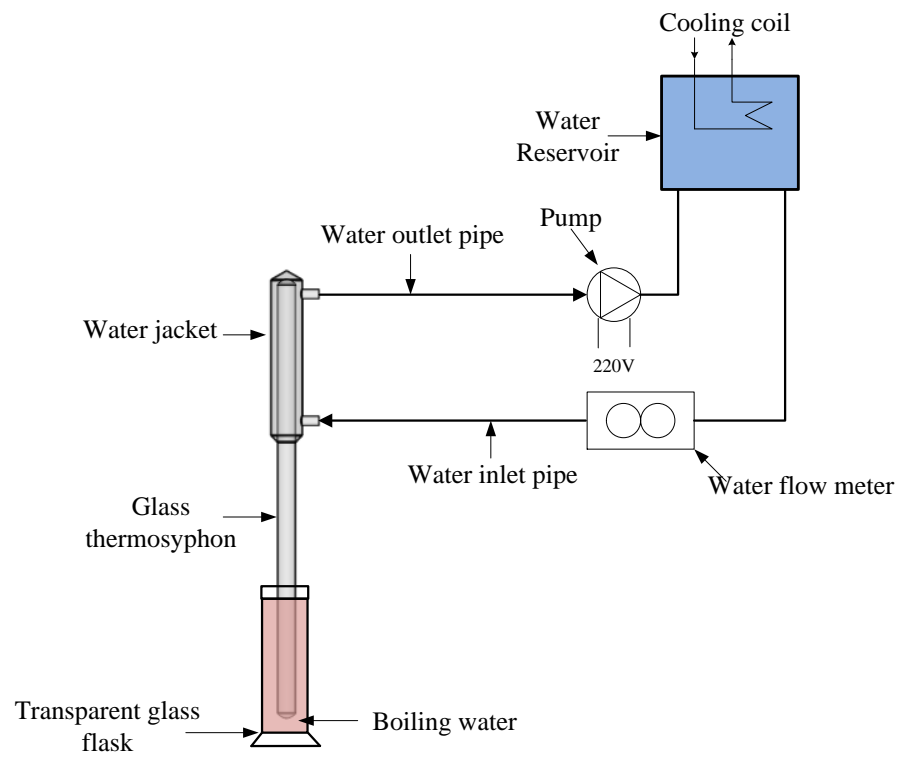

Figure 10: A glass thermosyphon experimental apparatus 


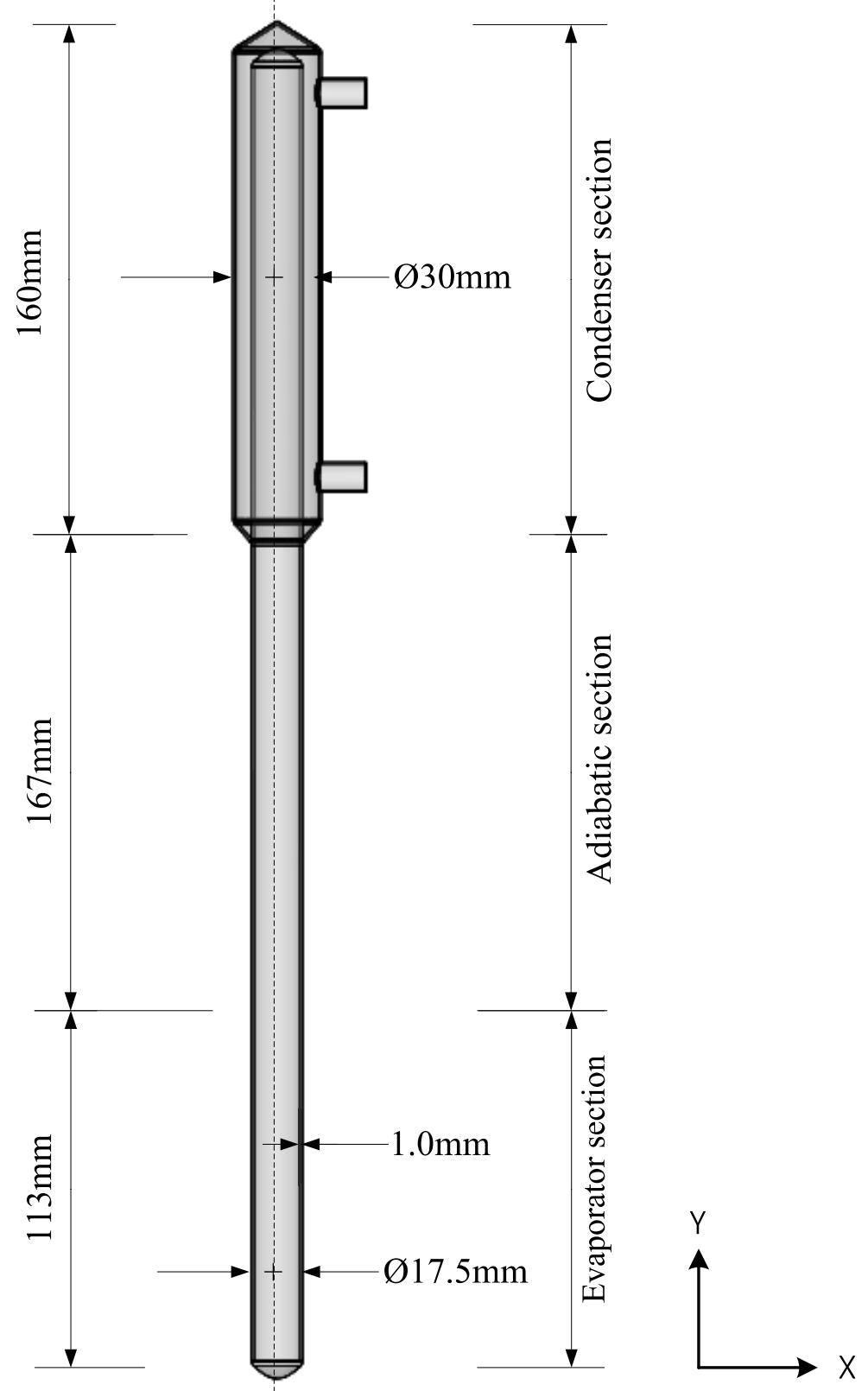

Figure 11: A transparent glass thermosyphon dimensions 


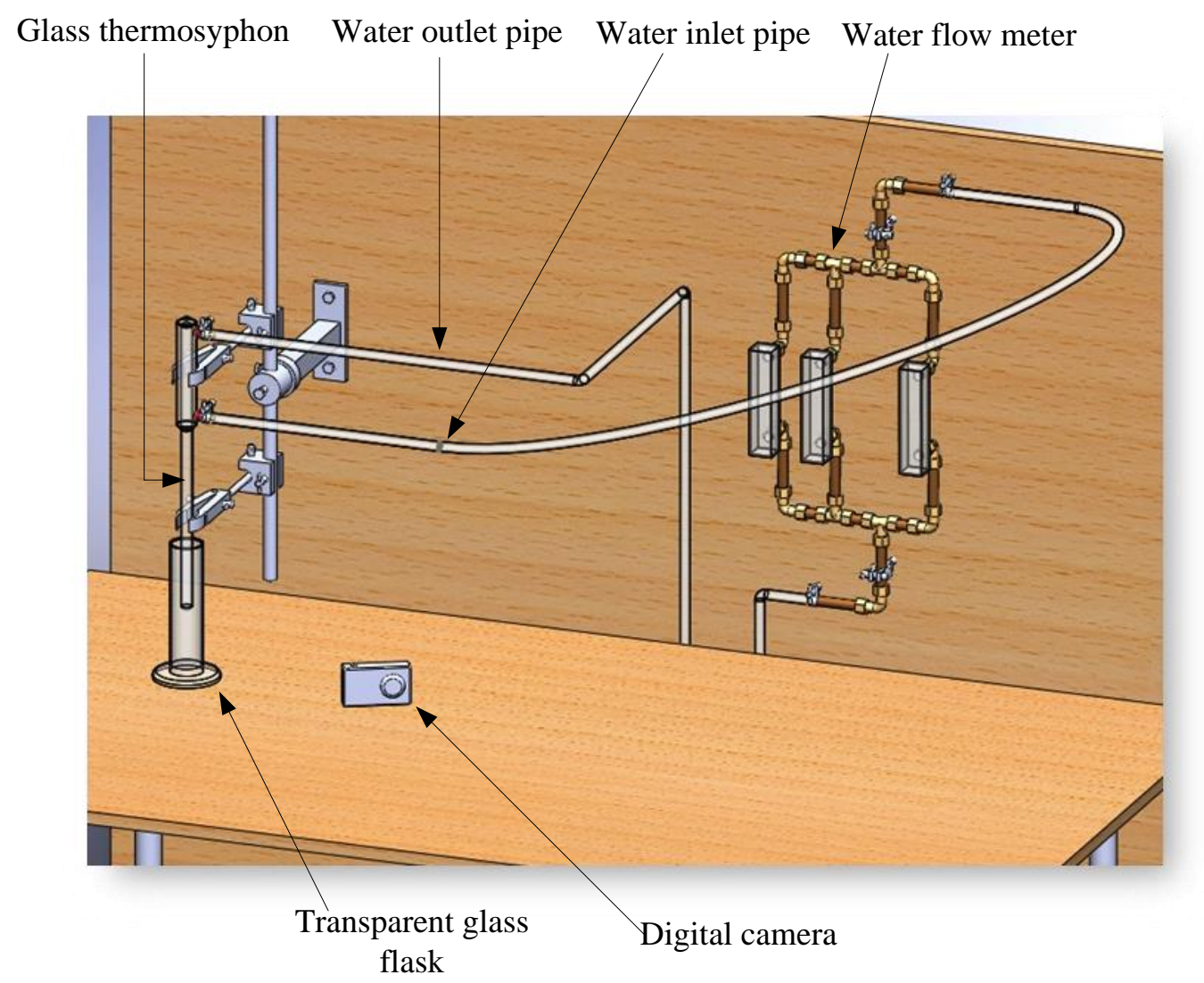

Figure 12: A glass thermosyphon experimental apparatus framwork 


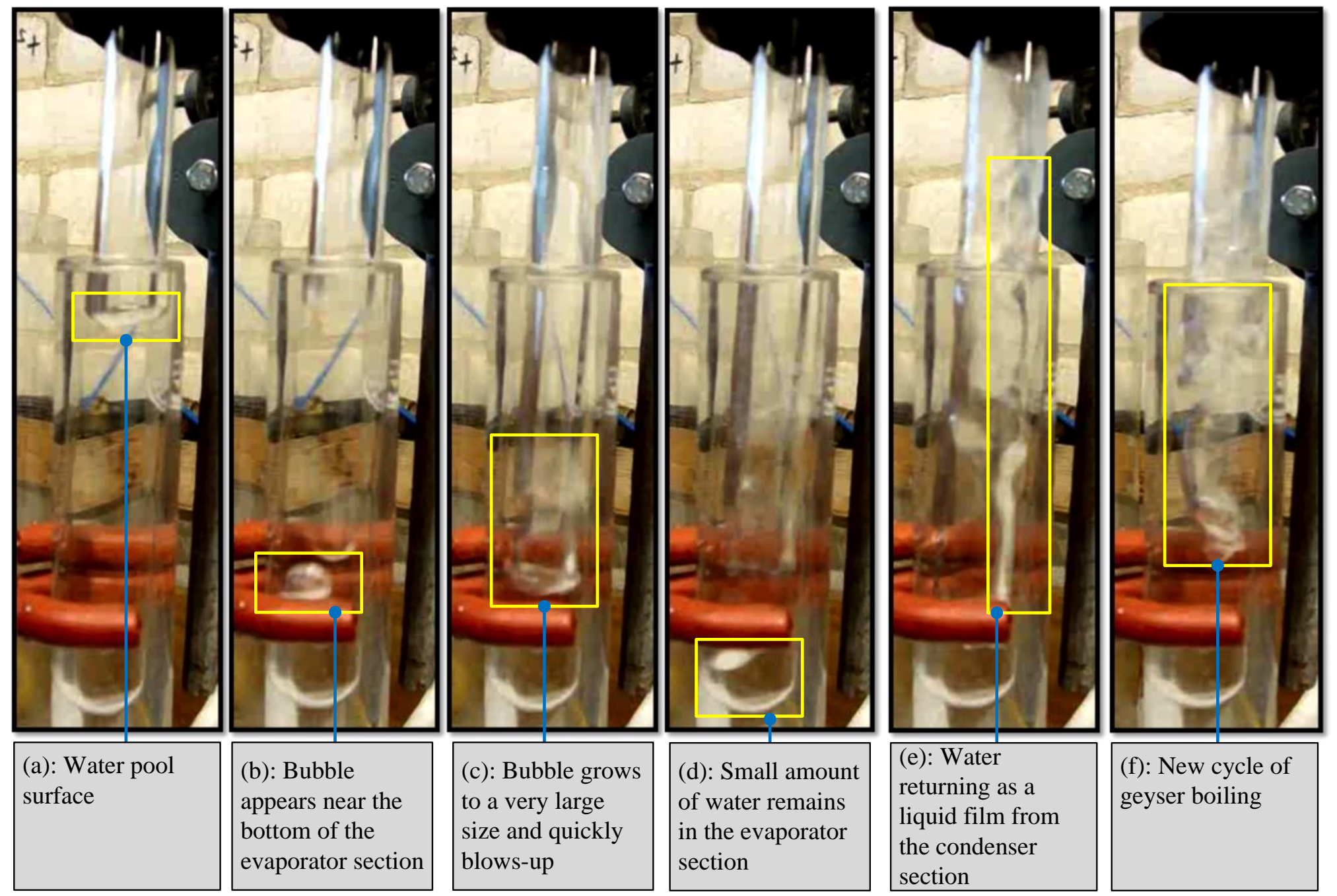

Figure 13: Visualisation of geyser boiling using transparent glass thermosyphon 


\section{THREE-DIMENSIONAL CFD SIMULATION OF A R134a-FILLED THERMOSYPHON FOR A POWER THROUGHPUT OF 30W}

In order to show that the developed three-dimensional CFD model has the ability to reproduce the difference in pool boiling behaviour between different working fluids, refrigerant R134a has been simulated and a three-dimensional flow visualisation of pool boiling and film condensation during the operation of the R134a-filled thermosyphon was observed and shown in Figure14.

Consequently, three phases have been defined for the CFD simulation of the thermosyphon filled with R134a and cooled by water through the condenser section's heat exchanger. In particular, the two main phases defined in the CFD model are the liquid phase of R134a (filling the total volume of the evaporator section) and the vapour phase of R134a. These phases were adopted in the fluid region of the thermosyphon, where phase change occurs between them during the boiling and condensation processes. The third phase is the cooling fluid of the condenser section's heat exchanger, which is water. This phase has been adopted in the annular space of the heat exchanger, as shown in Figure1 (Section A-A), where forced convection heat transfer takes place between the condenser wall and the cooling fluid.

In order to show the three-dimensional pool boiling, three-dimensional vapour bubbles and the surface liquid pool in the evaporator section have been visualised, as illustrated in Figure14. Heat is applied through the evaporator section where a liquid pool of R134a exists, as shown in Figure14 at $\mathrm{t}=0.0 \mathrm{~s}$. Vapour bubbles are then generated in the evaporator section and moved to the liquid pool surface releasing their content of vapour, as shown in Figure14 at $\mathrm{t}=0.12 \mathrm{~s}$. In the condenser section, the saturated vapour condenses along the inner wall and gravity then returns the condensate back to the evaporator section as a falling liquid film, as clearly seen in Figure 14 at $\mathrm{t}=0.21 \mathrm{~s}$ and $0.56 \mathrm{~s}$. The continuous liquid film then recharges the liquid pool in the evaporator section, as shown in Figure14 at $\mathrm{t}=3.5 \mathrm{~s}$ to $5.8 \mathrm{~s}$.

Furthermore, due to the critical nucleation site radiuses, the pool boiling behaviour of $\mathrm{R} 134 \mathrm{a}$ is significantly different to that of water, as very small bubbles grow during 
the pool boiling of R134a-filled thermosyphon; as a result, the position of the liquid pool surface is not raised, as clearly seen in Figure 8 and Figure14. For that reason, it can be noted that geyser boiling is not observed in this case. 


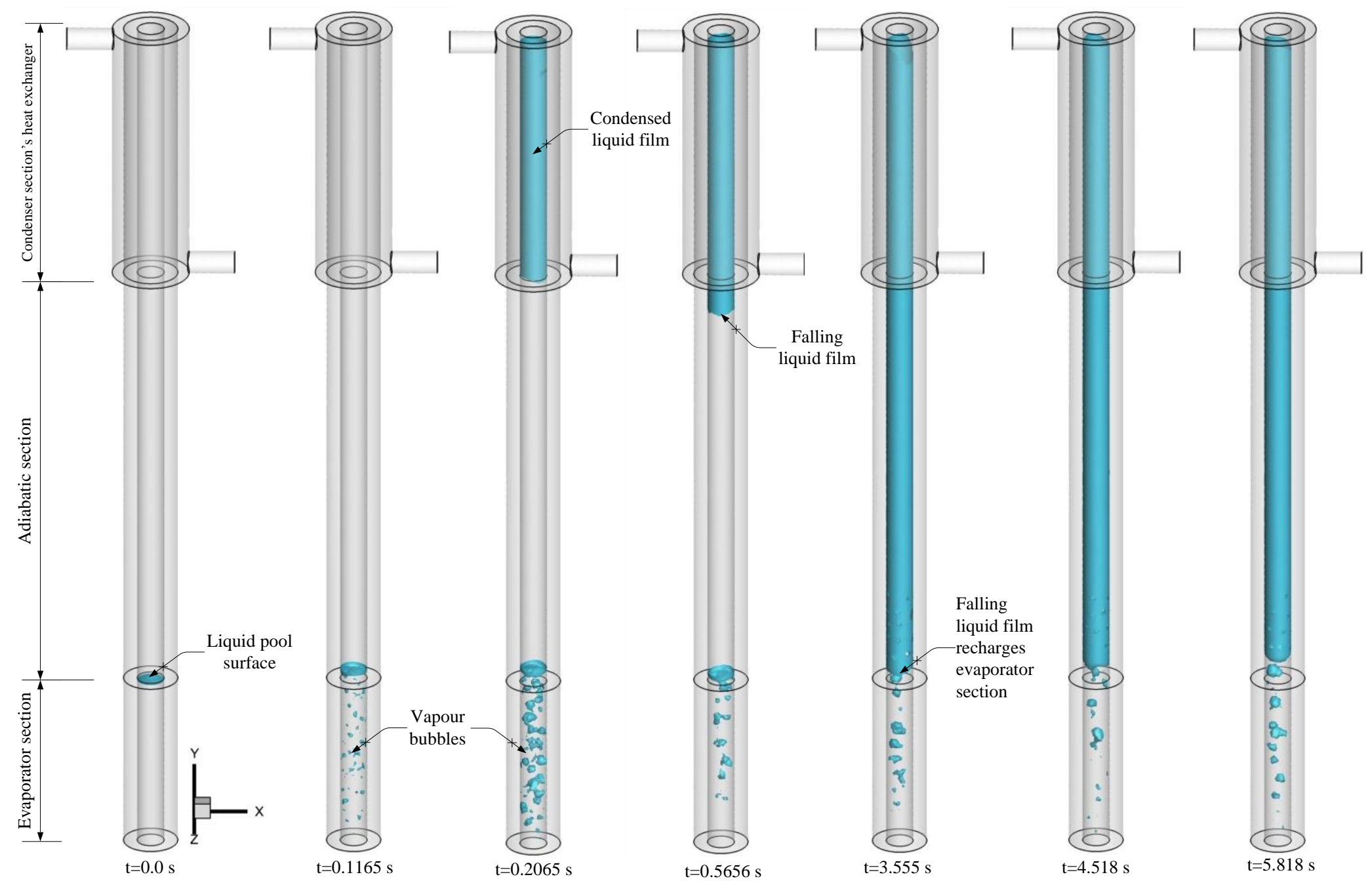

Figure14: Three-dimensional CFD modelling of evaporation and condensation for a thermosyphon charged with R134a for a power throughput of $30 \mathrm{~W}$ 


\section{CONCLUSIONS}

The main objective of this study is the development of a comprehensive three-dimensional CFD model that allows the simulations of the evaporation and condensation processes in a wickless heat pipe, and the simulation of the double pipe heat exchanger in the condenser section cooling system. The simulation of these processes is one of the steps required to model the complete system, in order to consider the phase change material during the boiling and condensation mass transfer, by using the UDFs and VOF methods.

The CFD simulation results of this study show that FLUENT with the VOF and UDFs can successfully model the complex phenomena inside the wickless heat pipe. It is observed from the flow visualisation that the CFD simulation was able to reproduce the multiphase flow characteristics of pool boiling in the evaporator section. The CFD visualisation results of this study have demonstrated the abilities of the CFD model to simulate the pool boiling behaviour for different working fluids, namely water and R134a. The three-dimensional CFD simulation has also successfully predicted and visualised, for the first time, a flow pattern that takes place with water at low power throughput, known as geyser boiling. The heat throughput has a significant effect on the characteristics of the geyser boiling in which the geyser boiling phenomenon does not appear for higher heat throughput. The geyser boiling simulations have been visually validated with a transparent glass thermosyphon experiment. 


\section{REFERENCES}

[1] Jouhara H, Meskimmon R. Experimental investigation of wraparound loop heat pipe heat exchanger used in energy efficient air handling units. Energy 2010;35:4592-9. doi:10.1016/j.energy.2010.03.056.

[2] Jouhara H, Ezzuddin H. Thermal performance characteristics of a wraparound loop heat pipe (WLHP) charged with R134A. Energy 2013;61:128-38. doi:10.1016/j.energy.2012.10.016.

[3] Liu Y, Wang H, Prasad AK, Advani SG. Role of heat pipes in improving the hydrogen charging rate in a metal hydride storage tank. Int J Hydrogen Energy 2014;39:10552-63. doi:10.1016/j.ijhydene.2014.04.197.

[4] Wong S-C, Hsiao H-C, Lo K-F. Improving temperature uniformity and performance of CO preferential oxidation for hydrogen-rich reformate with a heat pipe. Int $\mathrm{J}$ Hydrogen Energy 2014;39:6492-6. doi:10.1016/j.ijhydene.2014.02.088.

[5] Zikanov O. Essential Computational Fluid Dynamics. New Jersey: John Wiley \& Sons; 2010.

[6] Sayma A. Computational Fluid Dynamics. Denmark: Ventus Publishing ApS; 2009.

[7] Jouhara H, Robinson AJ. An Experimental Study of Small-Diameter Wickless Heat Pipes Operating in the Temperature Range $200^{\circ} \mathrm{C}$ to $450^{\circ} \mathrm{C}$. Heat Transf Eng 2009;30:1041-8. doi:10.1080/01457630902921113.

[8] Fadhl B, Wrobel LC, Jouhara H. Numerical modelling of the temperature distribution in a two-phase closed thermosyphon. Appl Therm Eng 2013;60:122-31. doi:10.1016/j.applthermaleng.2013.06.044.

[9] Kerrigan K, Jouhara H, O’Donnell GE, Robinson AJ. Heat pipe-based radiator for low grade geothermal energy conversion in domestic space heating. Simul Model Pract Theory 2011;19:1154-63. doi:10.1016/j.simpat.2010.05.020.

[10] Jiao B, Qiu LM, Zhang XB, Zhang Y. Investigation on the effect of filling ratio on the steady-state heat transfer performance of a vertical two-phase closed thermosyphon. Appl Therm Eng 2008;28:1417-26. doi:10.1016/j.applthermaleng.2007.09.009. 
[11] Kafeel K, Turan A. Simulation of the response of a thermosyphon under pulsed heat input conditions. Int J Therm Sci 2014;80:33-40.

doi:10.1016/j.ijthermalsci.2014.01.020.

[12] Amatachaya P, Srimuang W. Comparative heat transfer characteristics of a flat twophase closed thermosyphon (FTPCT) and a conventional two-phase closed thermosyphon (CTPCT). Int Commun Heat Mass Transf 2010;37:293-8. doi:10.1016/j.icheatmasstransfer.2009.11.004.

[13] Alizadehdakhel A, Rahimi M, Alsairafi AA. CFD modeling of flow and heat transfer in a thermosyphon. Int Commun Heat Mass Transf 2010;37:312-8. doi:10.1016/j.icheatmasstransfer.2009.09.002.

[14] Zhang M, Liu Z, Ma G, Cheng S. Numerical simulation and experimental verification of a flat two-phase thermosyphon. Energy Convers Manag 2009;50:1095-100. doi:10.1016/j.enconman.2008.12.001.

[15] Annamalai S, Ramalingam V. Experimental investigation and CFD analysis of a air cooled condenser heat pipe. Therm Sci 2011;15:759-72. doi:10.2298/TSCI100331023A.

[16] Lin Z, Wang S, Shirakashi R, Winston Zhang L. Simulation of a miniature oscillating heat pipe in bottom heating mode using CFD with unsteady modeling. Int J Heat Mass Transf 2013;57:642-56. doi:10.1016/j.ijheatmasstransfer.2012.09.007.

[17] Khazaee I, Hosseini R, Noie SH. Experimental investigation of effective parameters and correlation of geyser boiling in a two-phase closed thermosyphon. Appl Therm Eng 2010;30:406-12. doi:10.1016/j.applthermaleng.2009.09.012.

[18] Lin TF, Lin WT, Tsay YL, Wu JC, Shyu RJ. Experimental investigation of geyser boiling in an annular two-phase closed thermosyphon. Int J Heat Mass Transf 1995;38:295-307. doi:10.1016/0017-9310(95)90019-5.

[19] Negishi K, Sawada T. Heat transfer performance of an inclined two-phase closed thermosyphon. Int J Heat Mass Transf 1983;26:1207-13. doi:10.1016/S00179310(83)80175-6.

[20] Fadhl B, Wrobel LC, Jouhara H. CFD modelling of a two-phase closed thermosyphon charged with R134a and R404a. Appl Therm Eng 2015;78:482-90. doi:10.1016/j.applthermaleng.2014.12.062. 
[21] Anderson J. Computational Fluid Dynamics: The Basics with Applications. New York: McGraw-Hill; 1995.

[22] ANSYS I. ANSYS FLUENT Theory Guide (Release 13.0). Multiphase Flows. 2010.

[23] Jouhara H, Robinson AJ. Experimental investigation of small diameter two-phase closed thermosyphons charged with water, FC-84, FC-77 and FC-3283. Appl Therm Eng 2010;30:201-11. doi:10.1016/j.applthermaleng.2009.08.007.

[24] Brackbill J., Kothe D., Zemach C. A continuum method for modeling surface tension. J Comput Phys 1992;100:335-54. doi:10.1016/0021-9991(92)90240-Y.

[25] Sakintuna B, Lamaridarkrim F, Hirscher M. Metal hydride materials for solid hydrogen storage: A review. Int J Hydrogen Energy 2007;32:1121-40. doi:10.1016/j.ijhydene.2006.11.022.

[26] Chung CA, Yang S-W, Yang C-Y, Hsu C-W, Chiu P-Y. Experimental study on the hydrogen charge and discharge rates of metal hydride tanks using heat pipes to enhance heat transfer. Appl Energy 2013;103:581-7. doi:10.1016/j.apenergy.2012.10.024.

[27] Nasrallah S, Jemni A. Heat and mass transfer models in metal-hydrogen reactor. Int J Hydrogen Energy 1997;22:67-76. doi:10.1016/S0360-3199(96)00039-0.

[28] Olabi AG. The 3rd international conference on sustainable energy and environmental protection SEEP 2009 - Guest Editor's Introduction. Energy 2010;35: 4508 - 4509. doi: 10.1016/j.energy.2010.09.053.

[29] Oi T, Maki K, Sakaki Y. Heat transfer characteristics of the metal hydride vessel based on the plate-fin type heat exchanger. J Power Sources 2004;125:52-61. doi:10.1016/S0378-7753(03)00822-X.

[30] Vasiliev LL, Kanonchik LE, Kulakov AG, Babenko VA. Hydrogen storage system based on novel carbon materials and heat pipe heat exchanger. Int J Therm Sci 2007;46:914-25. doi:10.1016/j.ijthermalsci.2006.11.020.

[31] Vasiliev LL. Heat pipes in modern heat exchangers. Appl Therm Eng 2005;25:1-19. doi:10.1016/j.applthermaleng.2003.12.004.

[32] Garrison SL, Hardy BJ, Gorbounov MB, Tamburello DA, Corgnale C, VanHassel BA, et al. Optimization of internal heat exchangers for hydrogen storage tanks 
utilizing metal hydrides. Int J Hydrogen Energy 2012;37:2850-61.

doi:10.1016/j.ijhydene.2011.07.044.

[33] Mayer U, Groll M, Supper W. Heat and mass transfer in metal hydride reaction beds: Experimental and theoretical results. J Less Common Met 1987;131:235-44. doi:10.1016/0022-5088(87)90523-6.

[34] Tong L, Chen J, Cao X, Yang S, Liao S, Deng J, et al. Visualization experiments on the geyser boiling-induced instability in vertical circular tube at low-pressures. Ann Nucl Energy 2015;77:487-97. doi:10.1016/j.anucene.2014.12.003.

[35] Ong KS, Haider-E-Alahi M. Performance of a R-134a-filled thermosyphon. Appl Therm Eng 2003;23:2373-81. doi:10.1016/S1359-4311(03)00207-2.

[36] Olabi AG. 100\% sustainable energy. Energy 2014;77:1-5. doi:10.1016/j.energy.2014.10.083. 